\title{
The Role of Laser in Diagnosis and Treatment of Pulp Pathology
}

\author{
Salma B A Abdo ${ }^{1,2 *}$ and Amera Alkaisi ${ }^{2}$ \\ ${ }^{1}$ Dental Department, Mediclinic Hospitals Middle East, Abu Dhabi, UAE and \\ Alfarabi University College, Iraq \\ ${ }^{2}$ Department of Dentistry, Alfarabi University College, Baghdad, Iraq \\ *Corresponding Author: Salma B A Abdo, Dental Department, Mediclinic Hospitals \\ Middle East, Abu Dhabi, UAE.
}

Received: October 11, 2021

Published: October 29, 2021

(C) All rights are reserved by Salma B A Abdo and Amera Alkaisi.

\begin{abstract}
In dentistry, the use of lasers has grown in popularity. It has improved the outcome of dental procedures and prognosis, as evidenced by numerous publications in dentistry generally. In endodontic technology, laser was introduced to improve the results of normal treatments by removing more debris and smear layer from the canal and enhancing cleaning ability. Mechanical cleaning, chemical irrigation, and an ultrasonic instrument have all been used to enhance root canal cleanliness. Nowadays, lasers have had a revolutionary impact on endodontics; they are mostly utilized for disinfecting root canals with improved outcomes and the ability to enter into more complicated root canal anatomy, such as the lateral canal. The goal of the current article was to give an idea about the current and future applications of lasers in clinical endodontics include, diagnostics of the pulp, non- invasive access cavity, pulp capping and pulpotomy, root canal debridement and shaping, $3 \mathrm{D}$ obturation and retreatment and endodontic surgery.
\end{abstract}

Keywords: Endodontics; Laser; Pulpal Diagnosis Category; Apical Surgery

\section{Introduction}

Endodontic treatment aims to remove infected pulp tissue that could encourage growth of microbial and prevent pushing the debris past the apical foramen, which could cause inflammation and microorganism growth at the periapical area [1]. Endodontic therapy has limitations, such as diverse dimensions and morphologies of laterally located canals [2], apical ramifications, complexity of anatomy and the difficulty of normal irrigants penetrating into the laterally located canals. The laser was introduced into endodontics to improve current treatments by boosting cleaning capabilities via light radiation.

\section{History of lasers in dentistry}

Newton in 1704, defined light as it consists of stream of particles. In 1880, Maxwell's in his Electromagnetic (EM) theory, light was defined as EM fields with fast vibrations caused by charged particle oscillations [3]. The abbreviation LASER represent L for Light A for Amplification, S for Stimulated, E for Emission and R for Radiation The "maser" (microwave stimulated emission of radiation) was invented in 1958 by Charles Townes and Arthur Schawlow [4]. Leon Goldman, a physicist, was the first to use a ruby laser in vivo in 1965. He tried it on his dentist brother Bernard's dental tissues, but it didn't work because of the significant heat damage [5]. Weichman and Johnson [6] employed $\mathrm{CO}_{2}$ laser in vitro to close the apical foramen in 1971, but their aim was not fulfilled. One year later, Weichman and Johnson [6] attempted for sealing the apical foramen using $\mathrm{Nd}$ YYAG laser and they gain further information about interaction between laser's and dentine. At that time, the use of laser for endodontic purpose was impossible. The Er:YAG laser is the first hard tissue laser in dentistry have approval from FDA in 1997 and regarded as in dentistry, in the next year Er, Cr:YSGG laser was developed [7], dramatically increasing the lasers used in clinics. 


\section{Classification of lasers}

Lasers are classified based on their active light medium, clinical applications and light spectrum (Table 1-3).

\begin{tabular}{|c|c|c|c|c|}
\hline $\begin{array}{l}\text { Ultravio- } \\
\text { let }\end{array}$ & Visible & Near infrared & $\begin{array}{l}\text { Medium } \\
\text { infrared }\end{array}$ & Far infrared \\
\hline \multirow[t]{6}{*}{$\begin{array}{l}\text { Excimer } \\
308 \mathrm{~nm}\end{array}$} & $\begin{array}{l}\text { Diode } 445 \\
\text { nm (Blue) }\end{array}$ & Diode $810 \mathrm{~nm}$ & $\begin{array}{c}\text { Er,Cr:YSGG } \\
2780 \mathrm{~nm}\end{array}$ & $\mathrm{CO}_{2} 9300 \mathrm{~nm}$ \\
\hline & $\begin{array}{c}\text { Argon } 470 \\
-488 \mathrm{~nm} \\
\text { (Blue) } \\
\text { Argon } 514 \\
\text { nm (Green) }\end{array}$ & Diode $940 \mathrm{~nm}$ & $\begin{array}{c}\text { Er:YAG } 2940 \\
n m\end{array}$ & $\mathrm{CO}_{2} 9600 \mathrm{~nm}$ \\
\hline & $\begin{array}{c}\text { KTP } 532 \mathrm{~nm} \\
\text { (Green) }\end{array}$ & Diode $970 \mathrm{~nm}$ & & $\begin{array}{c}\mathrm{CO}_{2} 10,600 \\
\mathrm{~nm}\end{array}$ \\
\hline & $\begin{array}{c}\text { Diode 635- } \\
675 \mathrm{~nm} \\
(\text { Red })\end{array}$ & Diode 1064 nm & & \\
\hline & & $\begin{array}{c}\text { Nd:YAG1064 } \\
\text { nm }\end{array}$ & & \\
\hline & & $\begin{array}{c}\mathrm{Nd}: Y A P \\
\mathrm{~nm}\end{array}$ & & \\
\hline
\end{tabular}

Table 1: Classification of lasers according to their wavelength position on the electromagnetic spectrum of light.

\begin{tabular}{|l|c|c|c|}
\hline Soft tissue lasers & $\begin{array}{c}\text { Hard and soft } \\
\text { tissue lasers }\end{array}$ & LLLT & Diagnosis \\
\hline $\begin{array}{l}\text { Diodes } \\
445>1064 \mathrm{~nm}\end{array}$ & $\begin{array}{c}\text { Er,Cr:YSGG, } \\
\text { Er:YAG }\end{array}$ & $\begin{array}{c}\text { Diodes } \\
445>1064 \\
\mathrm{~nm}\end{array}$ & $405 \mathrm{~nm} 655 \mathrm{~nm}$ \\
\hline $\mathrm{Nd}$ :YAG, Nd:YAP & $\mathrm{CO}_{2} 9300 \mathrm{~nm}$ & & \\
\hline
\end{tabular}

Table 2: Calcification of laser dental lasers according to clinical applications.

\begin{tabular}{|l|c|c|c|c|}
\hline $\begin{array}{c}\text { Solid-state } \\
\text { laser }\end{array}$ & Gas laser & $\begin{array}{c}\text { Liquid } \\
\text { laser }\end{array}$ & $\begin{array}{c}\text { Semiconductor } \\
\text { laser }\end{array}$ & Excimers \\
\hline Nd:YAG & Argon & Argon Florid \\
Diode & $\begin{array}{c}\text { Carbon } \\
\text { dioxide }\end{array}$ & Dyes & Hybrid Silicon & $\begin{array}{c}\text { Krypton } \\
\text { florid }\end{array}$ \\
Er:YAG & & & Xenon Florid \\
\hline
\end{tabular}

Table 3: Calcification of laser based on active light medium.

\section{Mechanism of action}

Lasers are created when electrons in atoms absorb energy from an electrical current or a laser in particular glasses, crystals, or gases. Excited electrons in the nucleus of an atom move from a lowenergy orbit to a higher-energy orbit, emitting photons when they return to their normal state.

These photons are "coherent with similar wavelength, this means that all the light waves' troughs and crests are in sync. On the other hand normal visible light is consist of several wavelengths that are not coherent. First, laser light has only one wavelength (one unique color), which is defined as the amount of energy released when an excited electron drops to a lower orbit. Second, laser light is directed, whereas a flashlight creates diffuse light. Laser light is coherent; it maintains its focus at long distances, up to and including the moon [7].

\section{Applications of lasers in endodontics}

Lasers in endodontic can be utilized for a various purpose [8]:

1. Pulpal diagnosis category.

2. Pulp capping and pulpotomy.

3. Non Invasive access cavity.

4. Root canal debridement and shaping

5. 3D obturation, and retreatment (removal of Gutta percha)

6. Endodontic surgery.

\section{Pulpal diagnosis category}

Tenland and Hollway invented Laser Doppler Flowmetry (LDF) in 1982 and 1983, respectively. They used it in micro- vascular systems for assessing blood flow [9] and diagnose the flow of blood in the pulp [10]. This technology uses a low powers of $1 \mathrm{MW}$ or 2 MW diode lasers and helium-neon [11]. Through the crown the beam of laser is directed to the pulp blood vessels. Laser beam frequency is doppler altered, and some of the light is scattered back from the tooth during the movement of red blood cells [10]. On the tooth surface photocell detects the reflected light, and its result is proportional to the blood cells velocity and their number [12]. The fundamental advantage of this procedure in comparison with electric pulp tester and other available vitality tests is that it determines the vitality of a tooth without relying on the presence of a painful sensation. LDF is an excellent indicator of pulp status of changes following root fracture horizontally [13]. Furthermore, blood flow and pulp vitality may be retained in teeth that have recently been traumatized or are placed in a portion of the jaw that may be damaged after orthognathic surgery, whereas sensibility may be lost [11]. The primary benefit of this method in comparison 
with pulp testing electrically or by using another vitality tests is that it assesses a tooth's vitality without relying on the presence of a painful sensation. Following a horizontal root fracture, LDF is an effective indication of changes in pulp quality [13]. Furthermore, in teeth that have recently been injured or are placed in an area of the jaw that may after orthognathic surgery be damaged, blood flow and pulp viability may be preserved, however sensation may be lost [10]. There are certain limits to Laser Doppler Flowmetry; for example, laser reflection may be difficult to gain from some teeth; however, the Incisors with thin dentin and enamel have no difficulty. Pulpal blood flow may vary in molars due to thicker enamel and dentin with pulp position is different in the tooth [14]. Furthermore, for correct assessment, incomplete calibration by the manufacturer and discrepancies in the output of the sensor may necessitate the use of numerous probes [14]. If equipment costs and clinical application improve, Laser Doppler Flowmetry could be employed for young children and patients with communication challenges and whose replies are not always trustworthy [10].

\section{Pulp capping and pulpotomy}

By vaporizing, coagulating, and small blood vessels sealing with a sterile wound, bloodless field pulpotomy procedures can be achieved with laser. $\mathrm{CO}_{2}$ was used by Melcer., et al. [15] in beagle dogs and monkeys for hemostasis following exposure of pulp tissue, while another study compared $\mathrm{CO}_{2}$ laser with calcium hydroxide for pulp capping directly, with results showing $68 \%$ success with calcium hydroxide and 89\% with laser after 12 months [16].

For a 12-month follow-up, one study compared the clinical, radiographic, and histopathologic effects of pulpotomy using the Nd:YAG laser to formocresol. The results demonstrate success rate clinical and radiological of $85.71 \%$ and $71.42 \%$ respectively [17]. $\mathrm{CO}_{2}$ lasers and Nd:YAG can be used; Hydroxyapatite of the dentin and enamel absorb $\mathrm{CO}_{2}$ laser energy very well, it induces ablation of the tissue, melting, and solidification [17]. Using $\mathrm{CO}_{2}$ laser with a wavelength of 9,600 $\mathrm{nm}$ in dogs showed no any visible damage to the pulpal tissue [18]. Pulsed Nd:YAG, low and intermediate power semiconductor diode lasers, $\mathrm{CO}_{2}, \mathrm{He}-\mathrm{Ne}$, were used for ablation and additional treatment for important amputation of the pulp [19]. The use of $\mathrm{a} \mathrm{CO}_{2}$ laser is time demanding, and several exposures may cause pulp tissue damage. Pulsed Nd:YAG should be used for pulp hemostasis, anti-inflammatory effect, sedation and activation of surviving cells of the pulpal because it induces pulp tissue damage and so has a poor success rate [19].

\section{Non-invasive access cavity preparation}

Starting with the first step and ending with the final procedure of root canal therapy, laser has been frequently employed
[14]. Er,Cr:YSGG (2,780 nm) and Er:YAG (2,940 nm) lasers can be utilized for access cavity preparation, root canal debridement, whereas Nd:YAG $(1,064 \mathrm{~nm})$ lasers can be employed for root canal wall preparation and hemorrhage control [20]. When a $15 \mathrm{~Hz} / 1.5$ W pulsed Nd:YAG laser is employed in order to close the dentinal tubules, the smear layer can be totally removed [21].

\section{Root canal debridement and shaping}

Nd:YAG, argon, and diode, erbium chromium: yttrium-scandium-gallium-garnet [Er,Cr:YSGG], with thin optical fiber or a hollow tube can transmit the released energy into the root canal in dentistry.

Laser irradiation can remove debris and the smear layer from the root canal walls after biomechanical instrumentation, and canal disinfection with laser has been thoroughly reported [22]. The same results were shown when Nd:YAG lasers were used to treat infected dentin surfaces with Candida species [23] and diode lasers with a wavelength of $980 \mathrm{~nm}$ have been shown to kill E. faecalis from infected bovine dentin disks by up to $97 \%$. Antimicrobial Photodynamic Therapy (APDT) is of 2 steps process that begins with the administration of a photosensitizer and ends with illumination of the sensitized tissues by light, resulting in a toxic photochemistry that kills the bacteria on target cells [23]. APDT is now regarded as a supplement to typical disinfection of the canal techniques, and it can be used in conjunction with mechanical equipment and chemical antimicrobials [24].

Researchers recently discovered a new photosensitizer formulation that is unique in terms of adapting and boosting antimicrobial efficiency for endodontics (APDT), penetrating efficiently into dentinal tubules, anti-biofilm capabilities, and anatomical challenges $[24,25]$.

Garcez., et al. [26] study the comparison between standard root canal therapy, the effectiveness of APDT, and the combination of the two treatment to remove bacteria reside in the infected canals. They found that root canal chemical cleaning decrease bacteria by $90 \%$, APDT by $95 \%$, and the combined treatment by $>98 \%$. Endodontic treatment with APDT completely removed all organisms that resist drugs while endodontic conventional cleaning alone greatly reduced the number of microbial species [27].

The efficacy of antimicrobial action of two APDT systems and two high-power lasers (Nd:YAG and Er:YAG) was compared to NaO$\mathrm{Cl}$ on E. faecalis. The most effective one in elimination of $E$. faecalis was $\mathrm{NaOCl}$. Er:YAG laser has a significant reduction in viable number, and the two commercial APDT systems weakly reduce bacterial number [28]. 
Another technology Photo-Activated Disinfection (PAD) using aspecific wavelength and photosensitizing dye to destroy bacteria in planktonic suspensions and cause disperse of bacterial membrane by producing reactive oxygen and species free radicals and laser-activated disinfection [29]. It has the ability to eliminate $E$. faecalis from straight root canals, when compared to conventional irrigation, sonic activated irrigation [30].

The combination of a low-energy Light-Emitting Diode (LED) lamp and Toluidine Blue 0 (TBO) with in Photodynamic Therapy (PDT) has the potential to be employed as a supplementary antibacterial method in traditional endodontic therapy [25].

Deleu., et al. [31] observed that significantly there is no differences between ultrasonically activated irrigation and laser activated irrigation. Many researches [32] found that the latter generated better outcomes than the former. The investigators strongly suggested that the endodontic tip be improved so that entire canal walls may be irradiated [11], as evidenced by a study that found that using Nd:YAG lasers in combination with mechanical enlargement and saline irrigation failed to kill black pigmented bacteria intervention [33]. Although good results were obtained using laser driven irrigation, the main disadvantage is apical ejection of the watered solution [34]. As a result, in 2010, the PIPS-tip, which stands for "Photon-Initiated Photoacoustic Streaming" [35], a novel erbium laser tip design was produced.

Instead of being placed into the root canal, this approach entails inserting a specific radial firing fiber tapered tip via the aperture. Pulsed laser operation induces photoacoustic shockwaves in the irrigant, allowing 3D movement while going through the root canal system. By using a small, sub-ablative energy pulse, the PIPS approach avoids the negative effects of heat on the dentinal walls that other treatments have (only $10 \mathrm{~mJ}$ or $20 \mathrm{~mJ}$ ). This powerful physical phenomenon is accomplished by the use of very short (50 microseconds) laser pulses that produce high peak strengths even at low pulse energies, resulting in increased smear layer and debris removal with little or no heat damage to the organic section of the dentin structure [35].

The PIPS system was found to have more effects in comparison with ultrasonic and sonic systems [36]. PIPS has several limitations [37]. For example, the emission of laser energy is directed along the root canal from the laser guide or the optical fiber tip, not necessarily to the lateral walls of root canal [38]. It is not possible to cover the canal surface uniformly using a laser that able to damage the periapical tissues thermally [39].

The PIPS approach was in vitro tested in $\mathrm{NaOCl}$ and EDT, the results demonstrated that biofilm and bacterial load in a three dimensions were reduced in the root canal [40]. Comparison between conical and flat tips were done, they discovered that conical tips have a three-fold higher optodynamic energy conversion efficiency than flat one. Comparing the PIPS tips 400/14 and 600/9 with the XPulse tips 400/14 and 600/14 with the same diameter of fiber revealed that the tips at the orifice level with constant pulse energy have a comparable results in removing debris out of the groove model root canal wall [41].

The diameter of fiber ( $20 \mathrm{~mJ}$ or $40 \mathrm{~mJ})$ are pulse time of $50 \mathrm{mi}$ croseconds and the setting at $40 \mathrm{~mJ}$ have better performance than at $20 \mathrm{Mj}$, however; with the $40 \mathrm{~mJ}$ energy, care should be taken [41].

At the moment, there are 2 methods to clean and disinfect the canals with endodontic fibers. The first method is by using the fiber in which the root canal should be dried. A spiral fiber motion is required because laser beam is straight forward, to expose the wall of the root canal, allowing removal of smear layer and debris, and biofilm interaction [41].

The second option is to employ the fiber itself in the irrigant, which can be performed in the root canal or at the level of the opening in the pulp chamber, with the goal of creating liquid motion or cavitation (Laser Activated Irrigation/LAI). Cavitation is accomplished by forming the bubbles of vapor, while liquid agitation is accomplished by expansion and exploding of bubbles. It is feasible to employ little energy and short activation durations with this technology. The combination produces large peak powers, which allows the liquid to be agitated without risk of damage by heat [41].

Unlike applications of laser traditionally, tapered PIPS tip is unique only required to be put in the pulp chamber and not inside the canal. This reduces larger devices needs to form larger canals, allowing irrigation solutions to reach apically removing vital and non-vital tissues, canal ramifications, killing the germs, and disinfecting the dentin tubules during treatment [36]. PIPS with $6 \% \mathrm{Na}$ $\mathrm{OCl}$ affective more than water + PIPS or irrigation with $6 \% \mathrm{NaOCl}$ only [38].

The PIPS impact was investigated by eliminating a biofilm in vitro with $6 \% \mathrm{NaOCl}$; the results showed that PIPS groups cleaned the infected dentin better than the Passive Ultrasonic Irrigation (PUI) group. The study's most interesting discovery was that the PIPS tip was placed $22 \mathrm{~mm}$ away from the target area, while passive irrigation, ultrasonic, and sonic were performed directly on the target area [42]. The organic component of the dentin structure [35]. 
3 D obturation and removal of gutta percha obturation material

Several studies was conducted to determine the use of lasers for gutta percha softening and obturating inside the root canal [43], however thermoplastic materials and devices development for this purposes made this applications time consuming and costly.

Obturation is the process of closing the root canal system in three dimensions to avoid leaking starting from the apical foramen to the coronal part of the teeth which are treated. Clinical success rates as high as $96.5 \%$ have been reported when the root canal is completely sealed.

System-B method, gutta-percha softened by Nd:YAG laser, and lateral condensation were used to compare leakage from the apex. The results showed that there were no differences between the three groups in micro leakage apically [44]. However, System-B and lateral condensation cause fewer leakage than that with guttapercha laser-softening group. When compared to traditional procedures, another study indicated that irradiation with Er:YAG laser $(170 \mathrm{~mJ}$ to $250 \mathrm{~mJ}, 2 \mathrm{~Hz}$ ) of the root canal had no effect on apical leakage following obturation [45]. They showed that using the Nd:YAG laser reduced apical leakage, and that using an Er:YAG laser beam $(200 \mathrm{~mJ}, 4 \mathrm{~Hz})$ for 60 seconds, the adhesion of epoxy resin based sealers improved comparing with zinc oxide eugenol sealers [46]. They also showed that increase in the frequency of lasers increases sealer adhesion regardless of independent on power level.

The effects of diode and Nd:YAG laser irradiation on apical sealing before filling the root canal with two distinct resin-based cements (EndoREZ and AH Plus and) [47], as seen in SEM.

The effectiveness of lasers in eliminating gutta-percha and sealant from the root canal space is one of the reasons for their use in nonsurgical retreatment [48]. In more than $70 \%$ of cases, the $\mathrm{Nd}$ :YAG laser at 3 output powers $(1 \mathrm{~W}, 2 \mathrm{~W}, 3 \mathrm{~W})$ was able to remove filling material, and in $55 \%$ of cases, it was able to remove broken instruments [48].

In vitro, a pulsed Nd:YAG laser was employed for removing two materials of endodontic obturator out of the canal. The results demonstrated that there is no methods completely remove the debris from the canal wall and the time needed to remove any canal obturating material with ablation by laser was less significantly than that needed for removing any of the root canal obturating materials by tweezers $[43,49]$. While the Nd:YAP laser was unable to totally remove debris and obturating material [50].

Low-Level Laser Therapy is feasible non pharmacologic approach for pain reduction. It improves pain following retreatment mandibular molars root canal [51].
Endodontic surgery, apical cavity preparation, retrograde filling and periapical curettage

Laser used in endodontic surgery are similar to that used in other oral surgery procedures, soft tissue lasers such as Diode, $\mathrm{Nd}$ :YAG; and $\mathrm{CO}_{2}$ can be used to have access to the periradicular area with a clean incision. The advantage of lasers in perapically surgical procedure, it does not generate aerosol as in conventional hand pieces, so that contamination can be reduced in the surgical environment by pathogens carried by blood [52].

The Er,Cr:YSGG or the Er:YAG lasers are indicated for sectioning the third part of the apex of the root and in preparing retrograde. The special characters of laser in surgical endodontic are: sterilization; absorb selectively, reduced scarring, faster wound healing, providing bloodless field, decrease the number of oral pathogens such as bacteria, good hemostasis, minimum pain, and no need for sutures [52]. Pulsed Nd:YAG and $\mathrm{CO}_{2}$ lasers can be used to treat sinus tract from periapical lesions. In dogs, apicoectomy was done in a study using $\mathrm{CO}_{2}$ laser, there was no improvement in the success rate after the operation, in spite of its ability to decrease permeability of the dentin [53].

A prospective study of 320 cases preparing the apex for a retrogrades apicoectomy, two groups were evaluated for healing enhancement using $\mathrm{CO}_{2}$ laser in one group and non for the second, the healing process did not improved with $\mathrm{CO}_{2}$ laser [54]. While $\mathrm{Nd}$ :YAG used in vitro to test penetration of dye and bacteria [55] the result showed penetration of dye reduced as well as bacteria through roots which was resected. The authors claimed that the reduction in in the samples permeability may be related to the structural changes in dentin after application of laser [55].

Despite the fact that SEM inspection revealed that the hard tissue was melted, solidified, and recrystallized, the structural alterations were unequal, with the lased melted regions joined by areas identical to those of non-exposed samples. As a result, the dentin permeability was only partially reduced. It is reasonable to assume that glazed and homogeneous surfaces have lower permeability than incompletely glazed surfaces [56].

Rotundo., et al. [57] following preparations of cavity for retrograde filling in vitro, comparison for dye penetration between ultrasonic tools and Er:YAG was done. No significant difference was observed between the 2 groups, with no reduction in the permeability of dentin after using Er:YAG laser, because it does not undergo melting and sealing of the dentin tubules. In the other hand the permeability of the tooth that undergo resection and Nd;YAG laser treatment can be reduce [55]. 
Connective tissue response to the root part that has been resected for a period of time was followed to compare between bur and Nd:YAG laser cut, the result showed that there was delayed response in Nd:YAG laser cut than in bur cut [58].

Patients treated with Er:YAG lasers experienced less postoperative discomfort, as shown in multiple studies even in periodontal therapy [59], although low-level lasers can minimize postoperative pain in endodontic surgery [59].

Apical seal is the main aim of surgical endodontic, Researchers compared retrograde preparation cavity with Er,Cr:YSGG laser, ultrasonic retrotip and burs using MTA as retrograde filling, they found that microleakage was significantly less with Er,Cr:YSGG laser [60].

After resection and cavity preparation with a laser and other procedures, cracks on the root end showed no effect on the amount of cracks created on surfaces [61] and laser treatment may produce more uneven surfaces than a bur [62].

\section{Conclusion}

The applications of lasers have improved the prognosis and outcome of Endodontic treatments.

The goal of endodontics is to produce the best possible disinfection of the root canal system. Various methods for cleaning root canals have been documented in the literature, including chemical irrigation and the use of an ultrasonic device. Through the application of light energy, the laser improves the outcomes by enhancing cleaning ability, improving endodontic system decontamination, reducing permeability and micro-leakage, removal of the need for harmful solvents, and enhance apical endodontic surgery and curettage. Different types of lasers are a very valuable and simple technology that endodontists an employ with little risk to their patients.

\section{Bibliography}

1. Olivi G., et al. "Lasers in endodontics (Part I)". Roots (2011) 6-9.

2. Gulabivala K., et al. "Effects of mechanical and chemical procedures on root canal surfaces". Endodontic Topics 10 (2005): 103-122.

3. Einstein A. "Zur Quantentheorie der starhlung". Physikalische Zeitschrift 18 (1917): 121-128.

4. Purcell EM and Pound RV. "A nuclear spin system at negative temperature". Physical Review 81 (1951): 279-280.
5. Maiman TH. "Simulated optical radiation in ruby". Nature 187.4736 (1960): 493-494.

6. Weichman JA and Johnson FM. "Laser use in endodontics. A preliminary investigation". Oral Surgery, Oral Medicine, Oral Pathology, and Oral Radiology 31.3 (1971): 416-420.

7. Adrian JC., et al. "Laser and the dental pulp". Journal of the American Dental Association 83.1 (1971): 113-117.

8. Rai VK., et al. "Lasers in endodontics". International Journal of Oral Health and Medical Research 3.2 (2015): 47-54.

9. Mohammed H., et al. "Lasers in endodontics". Indo Global Journal of Pharmaceutical Sciences 06 (2019): 1415-1421.

10. Cohen S and Liewehr F. "Diagnostic procedures". In: Cohen S, Burns RC, editors. Pathways of the pulp. 8th edition. St. Louis (M0): Mosby (2002): 3-30.

11. Matsumoto K. "Lasers in endodontics". Dental Clinics of North America 44.4 (2000): 889-906.

12. Ebihara A., et al. "Pulpal blood flow assessed by laser Doppler flowmetry in a tooth with a horizontal root fracture". Oral Surgery, Oral Medicine, Oral Pathology, Oral Radiology, and Endodontology 81.2 (1996): 229-233.

13. Liao Q., et al. "Self-repaired process of a traumatized maxillary central incisor with pulp infarct after horizontal root fracture monitored by laser doppler flowmetry combined with tissue oxygen monitor". The Journal of Endodontics 43.7 (2017): 1218-1222.

14. Roeykens H., et al. "Reliability of laser Doppler flowmetry in a 2-probe assessment of pulpal blood flow". Oral Surgery, Oral Medicine, Oral Pathology, Oral Radiology, and Endodontology 87.6 (1999): 742-748.

15. Melcer J., et al. "Preliminary report on the effect of the $\mathrm{CO} 2$ laser beam on the dental pulp of the Macaca mulatta primate and the beagle dog". The Journal of Endodontics 11.1 (1985): $1-5$.

16. Moritz A., et al. "The $\mathrm{CO} 2$ laser as an aid in direct pulp capping". The Journal of Endodontics 24.4 (1998): 248-251.

17. Fried D., et al. "Permanent and transient changes in the reflectance of $\mathrm{CO} 2$ laser-irradiated dental hard tissues at lamb$\mathrm{da}=9.3,9.6,10.3$, and 10.6 microns and at fluences of 1-20 J/ cm2". Lasers in Surgery and Medicine 20.1 (1997): 22-31.

18. Wigdor HA and Walsh JT Jr. "Histologic analysis of the effect on dental pulp of a 9.6-microm CO (2) laser". Lasers in Surgery and Medicine 30.4 (2002): 261-266.

19. White JM., et al. "Intrapulpal temperatures during pulsed Nd:YAG laser treatment, in vitro". Journal of Periodontology 65.3 (1994): 255-259. 
20. Coluzzi DJ. "Fundamentals of dental lasers: science and instruments". Dental Clinics of North America 48.4 (2004): 751-770.

21. Kathari A and Ujariya M. "Lasers in endodontics: A review". Journal of Advanced Medical and Dental Sciences Research 3.1 (2014): 209-211.

22. Maden M., et al. "Determination of the effect of Nd:YAG laser irradiation through dentinal tubules on several oral pathogens". Lasers in Medical Science 28.1 (2013): 281-286.

23. De Oliveira BP., et al. "Photodynamic therapy in combating the causative microorganisms from endodontic infections". Dental Practice 8.3 (2014): 424-430.

24. Kishen A and Shrestha A. "Photodynamic therapy for root canal disinfection". In: Bettina Basrani, editor. Endodontic Irrigation: Chemical disinfection of the root canal system (2015): 237-251.

25. Zhu X., et al. "Comparison of the antibacterial effect and smear layer removal using photoninitiated photoacoustic streaming aided irrigation versus a conventional irrigation in singlerooted canals: an in vitro study". Photobiomodulation, Photomedicine, and Laser Surgery 31.8 (2013): 371-377.

26. Garcez AS., et al. "Photodynamic therapy associated with conventional endodontic treatment in patients with antibioticresistant microflora: a preliminary report". The Journal of Endodontics 36.9 (2010): 1463-1466.

27. Garcez AS., et al. "Antimicrobial mechanisms behind photodynamic effect in the presence of hydrogen peroxide". Photochemical and Photobiological Sciences 10.4 (2011): 483-490.

28. Meire MA., et al. "Effectiveness of different laser systems to kill Enterococcus faecalis in aqueous suspension and in an infected tooth model". International Endodontic Journal 42.45 (2009): 351-359.

29. Williams JA., et al. "The effect of variable energy input from a novel light source on the photoactivated bactericidal action of toluidine blue 0 on Streptococcus Mutans". Caries Research 37.3 (2003): 190-193.

30. Bago I., et al. "Antimicrobial efficacy of a high-power diode laser, photo-activated disinfection, conventional and sonic activated irrigation during root canal treatment". International Endodontic Journal 46.4 (2013): 339-347.

31. Deleu E., et al. "Efficacy of laser-based irrigant activation methods in removing debris from simulated root canal irregularities". Lasers in Medical Science 30.2 (2015): 831-835.

32. De Groot SD., et al. "Laser-activated irrigation within root canals: cleaning efficacy and flow visualization". International Endodontic Journal 42.12 (2009):1077-1083.
33. Granevik Lindstrom M., et al. "The Antibacterial effect of Nd:YAG laser treatment of teeth with apical periodontitis: a randomized controlled trial". The Journal of Endodontics 43.6 (2017): 857-863.

34. George R and Walsh LJ. "Apical extrusion of root canal irrigants when using Er:YAG and Er,Cr:YSGG lasers with optical fibers: an in vitro dye study". The Journal of Endodontics 34.6 (2008): 706-708.

35. DiVito E., et al. "The photoacoustic efficacy of an Er:YAG laser with radial and stripped tips on root canal dentin walls: an SEM evaluation". Journal of Dental Lasers 19 (2011): 156-161.

36. Arslan H., et al. "An in vitro comparison of irrigation using photon-initiated photoacoustic streaming, ultrasonic, sonic and needle techniques in removing calcium hydroxide". International Endodontic Journal 48.3 (2015): 246-251.

37. Stabholz A., et al. "The use of lasers in dentistry: principles of operation and clinical applications". Compendium of Continuing Education in Dentistry - Journals 24.12 (2003): 935-948.

38. Peters OA., et al. "Disinfection of root canals with photon-initiated photoacoustic streaming". The Journal of Endodontics 37.7 (2011): 1008-1012.

39. Lukac M and Pustovrh G. "Modeling Photoacoustic efficiency during Erbium laser endodontics". Journal / Laser and Health Academy 2 (2013): 1-7.

40. Jaramillo DE., et al. "Efficacy of photon induced photoacoustic streaming (PIPS) on the root canals infected with Enterococcus faecalis: a pilot study". Endodontic Practice 7 (2012): 2832.

41. Roeland JG., et al. "High-Power lasers in endodontics fiber placement for laser-enhanced endodontics: in the canal or at the orifice?" The Laser and Health Academy (2014).

42. Ordinola-Zapata R., et al. "Biofilm removal by $6 \%$ sodium hypochlorite activated by different irrigation techniques". International Endodontic Journal 47.7 (2014): 659-666.

43. Maden M., et al. "Evaluation of apical leakage of root canals obturated with Nd:YAG laser-softened gutta-percha, System-B, and lateral condensation techniques". The Journal of Contemporary Dental Practice 3 (2002): 16-26.

44. Viducić D., et al. "Removal of gutta-percha from root canals using an Nd:YAG laser". International Endodontic Journal 36.10 (2003): 670-673.

45. Anjo T., et al. "Removal of two types of root canal filling material using pulsed Nd:YAG laser irradiation". Photobiomodulation, Photomedicine, and Laser Surgery 22.6 (2004): 470-476.

46. Sousa-Neto MD., et al. "Effect of Er:YAG laser on adhesion of root canal sealers". Endodontics 28.3 (2002): 185-187. 
47. De Moura-Netto C., et al. "Influence of Nd:YAG and diode laser irradiation on apical sealing when associated with $\mathrm{AH}$ plus and EndoREZ endodontic cements". Photobiomodulation, Photomedicine, and Laser Surgery 25.5 (2007): 413-417.

48. Yu DG., et al. "Study on removal effects of filling materials and broken files from root canals using pulsed Nd:YAG laser". Journal of Clinical Laser Medicine and Surgery 18 (2000): 23-28.

49. Anić I and Matsumoto K. "Comparison of the sealing ability of lasersoftened, laterally condensed and low-temperature thermoplasticized gutta-percha". The Journal of Endodontics 21.9 (1995): 464-469.

50. Farge P., et al. "In vitro study of a Nd:YAP laser in endodontic retreatment". The Journal of Endodontics 24.5 (1998): 359363.

51. Arslan H., et al. "Effect of low level laser therapy on postoperative pain after root canal retreatment: A preliminary placebocontrolled, triple-blind, randomized clinical trial". The Journal of Endodontics 43.11 (2017): 1765-1769.

52. Payer M., et al. "The clinical effect of LLLT in endodontic surgery: a prospective study on 72 cases". Oral Surgery, Oral Medicine, Oral Pathology, Oral Radiology, and Endodontology 100.3 (2005): 375-379.

53. Friedman S., et al. "In vivo efficacy of various retrofills and of CO2 laser in apical surgery". Endodontics and Dental Traumatology 7.1 (1991): 19-25.

54. Bader G and Lejeune S. "Prospective study of two retrograde endodontic apical preparations with and without the use of C02 laser". Endodontics and Dental Traumatology 14.2 (1998): 75-78.

55. Stabholz A., et al. "Effects of Nd:YAG laser on apical seal of teeth after apicoectomy and retrofill". The Journal of Endodontics 18.8 (1992): 371-375.

56. Ebihara A., et al. "Application of Er:YAG laser to retrograde cavity preparation". Journal of Japanese Society for Laser Dentistry 9 (1998): 23-31.

57. Rotundo R., et al. "Lack of adjunctive benefit of Er:YAG laser in non-surgical periodontal treatment: a randomized splitmouth clinical trial". Journal of Clinical Periodontology 37.6 (2010): 526-533.

58. Maillet WA., et al. "Connective tissue response to root surfaces resected with Nd:YAG laser or burs". Oral Surgery, Oral Medicine, Oral Pathology, Oral Radiology, and Endodontology 82.6 (1996): 681-690.

59. Kreisler MB., et al. "Efficacy of low level laser therapy in reducing postoperative pain after endodontic surgery-a randomized double blind clinical study". International Journal of Oral and Maxillofacial Surgery 33 (2004): 38-41.
60. Premjith Shetty D., et al. "The effect of root end cavity preparation using Er,Cr:YSGG laser, ultrasonic retrotip, and bur on the apical microleakage of retrograde cavity filled with MTA Plus". Journal of Pharmacy and bio Allied Science 12.5 (2020): 299-303.

61. Aydemir S., et al. "Crack formation on resected root surfaces subjected to conventional, ultrasonic, and laser root-end cavity preparation". Photomedicine and Laser Surgery 32.6 (2014): 351-355.

62. Duarte MA., et al. "Evaluation of apical surface roughness after root resection: a scanning electron microscopic study". Oral Surgery, Oral Medicine, Oral Pathology, Oral Radiology, and Endodontology 104.6 (2007): e74-76.

Volume 5 Issue 11 November 2021

(C)All rights are reserved by Salma B A Abdo and Amera

Alkaisi. 